\title{
Normatividade, tecnicidade e/ou cientificidade da Biblioteconomia
}

\author{
Normativity, technicity and/or scientificity \\ of Librarianship
}

Jonathas Luiz CARVALHO SILVA'

\section{Resumo}

Este trabalho apresenta como problema uma questão que pode ser discutida a partir da seguinte pergunta: como ocorre o processo de construção da normatividade, da tecnicidade e/ou da cientificidade da Biblioteconomia? Discute também a construção de uma normatividade, tecnicidade e/ou cientificidade da Biblioteconomia, contemplando perspectivas em relação à organização e ao tratamento da informação, fontes, recursos e serviços de informação, práticas profissionais e estudos centrados nos usuários. O trabalho ainda analisa o conceito de norma e de técnica no âmbito da ciência e da pesquisa aplicada à Biblioteconomia, buscando refletir sobre a relevância da Ciência da Informação para os construtos normativos e científicos da Biblioteconomia. A metodologia é composta de uma pesquisa exploratória com delineamento bibliográfico. Conclui-se que a Biblioteconomia tem uma conotação essencialmente técnico-normativa, mas também uma concepção científica a partir das contribuições da Ciência da Informação no âmbito dos estudos de usuários, tecnologias e outros elementos, assim como de outras áreas do conhecimento de cunho social e tecnológico.

Palavras-chave: Biblioteconomia. Cientificidade. Normatividade. Tecnicidade.

\begin{abstract}
A condition is presented as a problematic issue that can be discussed from the following question: how does the process of construction of normativity, technicity and/or scientificity Librarianship occur? Discusses the construction of normativity, technicity and/or scientificity of Librarianship contemplating the prospects within the organization and processing of information, sources, resources and information services, professional practices and studies focusing on users. The study also examines the concept of norm and technique within the scope of science and applied research Librarianship, trying to reflect on the relevance of Information Science for the scientific and normative constructs of Librarianship. The methodology consists of an exploratory research with a bibliographic design. It was concluded that the Library has an essentially technical-normative connotation, but also has a scientific concept based on the contributions of Information Science to the context of user studies, technologies and other elements, in addition to other areas of knowledge of a social and technological nature.
\end{abstract}

Keywords: Librarianship. Scientificity. Normativity. Technicity.

\section{Introdução}

Ao longo do desenvolvimento da Biblioteconomia, seja no âmbito das perspectivas acadêmicas, seja no das práticas profissionais, um conjunto de percepções foi se consolidando. A Biblioteconomia, conforme Saracevic (1996, p.48), "Tem uma longa e orgulhosa história, remontando a três mil anos, devotada à organização, à preservação e ao uso dos registros gráficos humanos".

\footnotetext{
1 Professor, Universidade Federal do Ceará, Curso de Biblioteconomia. Av. Tenente Raimundo Rocha, s/n., Cidade Universitária, Campus Cariri, 63000-000, Juazeiro do Norte, CE, Brasil. E-mail: <jonathascarvalhos@yahoo.com.br>.

Recebido em 21/5/2012 e aceito para publicação em 31/8/2012.
} 
No âmbito dos conjuntos de percepções que foram se consolidando na Biblioteconomia, podem ser destacados os processos de organização e de tratamento da informação aplicados nos diversos tipos de bibliotecas (públicas, escolares, universitárias, especializadas, populares, entre outras), bem como as práticas profissionais que envolvem o bibliotecário, visando à efetiva promoção do acesso à informação para o usuário na construção de uma tessitura cognitiva e social.

Dias (2000) afirma que há um conjunto de práticas profissionais enviadas pelas bibliotecas (e evidentemente lideradas por bibliotecários) que incidem em um processo de qualificação e experiência para atuação podendo inadvertidamente destacar algumas funções: a) desenvolvimento de coleções (seleção dos materiais); b) classificação; c) catalogação; d) referência; e) pesquisa em sistemas de recuperação da informação; f) administração (planejamento estratégico, estudo do usuário, educação do usuário etc.).

Diante dessas funções e competências da biblioteca e do bibliotecário muito se fala sobre o caráter técnico-normativo que norteia a Biblioteconomia em seu bojo histórico. Todavia, é comum verificar no cotidiano da área uma tonalidade pejorativa ao mencionar a funcionalidade normativa e técnica da Biblioteconomia, o que limita suas potencialidades de discussão.

Desse modo, o presente trabalho apresenta como problema uma questão que pode ser discutida a partir da seguinte pergunta: como ocorre o processo de construção da normatividade, tecnicidade e/ou cientificidade da Biblioteconomia? O objetivo do trabalho é discutir a construção de uma normatividade, tecnicidade e/ou cientificidade da Biblioteconomia, contemplando perspectivas no seio da organização e do tratamento da informação, fontes, recursos e serviços de informação, práticas profissionais e estudos centrados nos usuários. O trabalho ainda analisa o conceito de norma e técnica no âmbito da ciência e da pesquisa aplicada à Biblioteconomia, buscando refletir sobre a relevância da Ciência da Informação para os construtos normativos e científicos da Biblioteconomia.

Assim, este trabalho estabelece uma trajetória que contempla os seguintes tópicos para compreender os processos de tecnicidade, normatividade e cientificidade da Biblioteconomia: a) reflexão sobre os conceitos de normatividade e tecnicidade aplicados aos estudos em Biblioteconomia; b) estudos em organização e tratamento da informação; c) estudos funcionalistas de bibliotecas e bibliotecários; d) estudos centrados nos usuários; e) relações entre Biblioteconomia e Ciência da Informação.

\section{Reflexão sobre os conceitos de normatividade e tecnicidade aplicados aos estudos em Biblioteconomia}

É muito comum ouvir falar na história da Biblioteconomia nos termos normas e técnicas. Aliás, esses termos indicam pretensões limitadas em termos de reflexão e criação, pois são enfaticamente conduzidos a atividades de execução e aplicação de forma aleatória.

Iniciando pela norma, é possível identificá-la a partir de significados em variadas áreas do conhecimento. Conforme o dicionário Ferreira (2010, p.534), o conceito de norma apresenta duas configurações que podem ser consideradas complementares: "Aquilo que se adota como base ou medida para a realização ou avaliação de algo; O que se tem como princípio, regra".

Desse modo, percebe-se que o conceito de norma apresenta, por um lado, um construto articulador para avaliação de algum fenômeno, e, por outro lado, como artefato institucional para um princípio ou regra. A origem do termo norma está ligada à filosofia grega, e o termo é entendido como motivos ou razões prescritivas (entendendo como prescritiva uma ordenação explícita ou precisa) referentes a uma determinada realidade do mundo. Conforme Husserl (2002, p.26), no âmbito da filosofia grega, importava"Buscar as normas necessárias, bem como todas as prescrições de natureza prática, úteis para dirigir de maneira prática o conhecimento e, em particular, o conhecimento científico".

As normas também estão ligadas aos diversos ramos do conhecimento, servindo de base para construção de princípios ou de regras de conduta, o que significa dizer que o conceito de norma também está intimamente ligado ao Direito, à Sociologia, à Linguística e a outras disciplinas e campos do conhecimento. Na contemporaneidade, a norma continua sendo sinônimo de princípio ou regra que atua de forma diversificada, de acordo com a realidade política e social, bem como 
conforme as necessidades de cada área do conhecimento. Na Biblioteconomia, é muito comum o uso do termo norma, que está, inclusive, atrelado ao seu próprio conceito. De acordo com Carvalho Silva (2010, p.63):

Podemos ainda conceber o conceito de Biblioteconomia relacionando aos contextos epistemológicos e etimológicos que está dividido em três palavras: biblio - teca - nomia. O primeiro está associado a livros, enquanto o segundo é relativo à caixa (algo que arranja, arruma ou organiza) e o terceiro quer dizer norma, isto é norma estabelecida para um determinado fim [...]. Isso significa dizer que a Biblioteconomia pode ser considerada, em sua essência, como uma norma estabelecida (conjunto de normas) para a organização de acervos de uma biblioteca que está embasada pelos códigos e materiais de catalogação, classificação, indexação e de outros instrumentos técnicos de organização, visando promover disseminação e acesso à informação a sociedade.

Assim, observa-se que a norma utilizada no conceito de Biblioteconomia contempla um conjunto de princípios para organização de acervos que tem como primado os estudos de representação da informação, especialmente pelos vieses da catalogação, classificação e indexação, além de outros elementos que promovam o acesso à informação.

É muito comum ainda o uso do termo norma na Biblioteconomia atrelado às Leis de Ranganathan (1931) ou aos estudos bibliométricos, que são contemplados a partir das Leis de Bradford, Lotka e Zipf, que servem como princípios de orientação profissional e epistemológica da e para a Biblioteconomia.

Os estudos bibliométricos se configuram como princípios normativos de cunho quantitativo, visando promover subsídios para a efetiva comunicação científica e sua recuperação da informação. Assim, a bibliometria pode ser considerada como um método quantitativo baseado na "utilização, de técnicas estatísticas" e, ainda, uma "aplicação da Matemática à Sociologia", considerando em caráter especial o resultado de contagens e medições (Goode; Hatt, 1969).

Atentando para o conceito de técnica, é possível observar, no dicionário Ferreira (2010, p.730), que se configura o "Conjunto de processos duma arte ou ciência". Isso significa dizer que a técnica não deve ser entendida como fator isolado, mas como elemento de intercorrências científicas e artísticas. De outro modo, a técnica é vista como processo de afirmação de uma autonomia político-social que envolve procedimentos artísticos ou científicos.

Vale ressaltar que a origem do termo técnica está intimamente concatenada ao pensamento da Grécia Antiga a partir do termo téchne, que apresenta basicamente o mesmo significado de arte (na Grécia Antiga, técnica e arte apresentavam o mesmo significado, que foi sendo separado no decorrer da história, especialmente a partir da Idade Moderna). Mesmo diante de um processo de construção histórica e filosófica em que houve uma separação do significado de técnica e arte, é muito comum ainda na contemporaneidade observar uma relação conceitual entre os dois termos, permitindo uma conotação de significação idêntica.

É possível identificar que a relação conceitual da Biblioteconomia como princípio artístico ocorre de forma latente por essa relação histórica, no seio da filosofia grega, entre o conceito de técnica idêntico ao de arte, o que presume a Biblioteconomia conceber princípios técnicos que valorizam um estado da arte para organização do conhecimento. Na contemporaneidade, principalmente no século XX, é muito comum a associação do significado de técnica à terminologia da tecnologia, de maneira que a técnica se constitui como processo para efetivação de resultados no campo da tecnologia.

Assim, é possível estabelecer que o conceito de técnica é bem mais amplo do que aquele pejorativamente empregado na Biblioteconomia, que contempla um conjunto de execuções arbitrariamente concebidas ou não. Pode-se comprovar essa amplitude no âmbito da pesquisa quando a técnica assume um papel de suma relevância para resolução de problemas empíricos e específicos. Embora a técnica não seja efetivamente uma ciência, ela parte dos mesmos pressupostos. Bunge (1980, p.31) estabelece uma diferenciação entre ciência e técnica quando diz que:

A diferença entre Ciência (básica ou aplicada) e técnica resume-se nisso: enquanto a primeira se propõe a descobrir leis que possam explicar a realidade em sua totalidade, a segunda se propõe a controlar determinados setores da realidade, com ajuda de todos os tipos de conheci- 
mento, especialmente os científicos. Tanto uma quanto outra partem de problemas, só que os problemas científicos são puramente cognoscitivos, enquanto que os técnicos são práticos. Ambas buscam dados, formulam hipóteses e teorias, e procuram provar essas ideias por meio de observações, medições, experiência ou ensaios. Porém, muitos desses dados, hipóteses e teorias empregados na técnica são tirados da Ciência e se referem sempre a questões controláveis, tais como estradas ou máquinas, pradarias ou bosques, minas ou rios, consumidores ou doentes, empregados ou soldados, e a sistemas compostos por homens e artefatos, tais como fábricas ou mercados, hospitais ou exércitos, redes de comunicação ou universidade etc. Ao técnico, não interessa o universo todo, e sim o que represente recurso natural ou artefato.

A técnica possui algumas características que a diferem da ciência. Em primeira instância, é pertinente considerar que a técnica pode produzir conhecimento científico, mesmo que não seja a finalidade principal. Aliás, a técnica utiliza o conhecimento científico para planejar suas ações. A diferença é que o objetivo da pesquisa científica é o de conhecer e explicar algumas questões, enquanto a técnica utiliza o conhecimento científico bem como outros tipos do conhecimento para atuar em uma situação prática de algum grupo social.

Pode-se dizer ainda que a técnica visa à produção de conhecimento para resolver problemas práticos, cotidianos e sociais, ou seja, a técnica para ser constituída como tal precisa chegar a seu campo de atuação, que pode ser uma biblioteca, arquivo, museu, fábrica, banco, mercado, hospital, shoppings, entre outros. Porém, comumente, a ação da técnica é específica, permitindo afirmar que não vai resolver necessariamente, por exemplo, os problemas estruturais de todas as bibliotecas, arquivos e museus, mas sim de um sistema de informação específico.

Aplicada à Biblioteconomia, a técnica deve ser vislumbrada como um instrumento de ação em centros de informação, especialmente bibliotecas a partir da proposição de instrumentos que facilitem os processos de organização, representação, tratamento, mediação, acesso, uso e apropriação da informação em contextos mais específicos que possam servir de modelos ou subsídios para construtos mais amplos.
O ponto áureo da tecnicidade e normatividade da Biblioteconomia se dá quando da utilização das Normas Técnicas de Informação e Documentação, que fazem parte do contexto de atuação da Biblioteconomia em torno de pesquisas, e principalmente, no que se refere as práticas e execuções profissionais de bibliotecários, estudantes, professores e pesquisadores da área.

A norma técnica pode ser entendida como um "Documento, estabelecido por consenso e aprovado por um organismo reconhecido, que fornece, para um uso comum e repetitivo, regras, diretrizes ou características para atividades ou seus resultados, visando à obtenção de um grau ótimo de ordenação em um dado contexto" (Esper, 2008, p.13).

Conforme a Associação Brasileira de Normas Técnicas (ABNT), em seu Comitê Brasileiro 14, a norma técnica de informação e documentação atua a partir da "Normalização no campo da informação e documentação, compreendendo as práticas relativas a bibliotecas, centro de documentação e informação, serviços de indexação, resumos, arquivos, Ciência da Informação e publicação". Essa norma de informação e documentação possui uma relação latente com as práticas biblioteconômicas, configurando-se como princípios e recomendações que estão inseridos no contexto cotidiano dos componentes da Biblioteconomia que trabalham com a normalização ou mesmo com recomendações especializadas na área de Biblioteconomia como serviços de indexação (Associação Brasileira de Normas Técnicas, 2006, p.1).

Por isso, as normas e as técnicas muitas vezes são vistas na Biblioteconomia de forma banal, como princípios arbitrários, cabendo à área apenas aplicá-los sem uma efetiva contestação. Todavia, é fundamental considerar que a norma técnica como uma recomendação deixa muitos pontos vazios de sentido, o que implica uma interpretação mais ampla por parte dos que trabalham com a normalização.

Pode-se ainda ressaltar a relevância da participação de bibliotecários, professores e pesquisadores da área no Comitê Brasileiro de Informação e Documentação para promover questionamentos e sugestões para o aprimoramento das técnicas e a uma compreensão mais ampla do significado de uma norma técnica para as atividades biblioteconômicas. 
Em suma, acredita-se que a Biblioteconomia possui um pouco de uma técnica voltada para um contexto artístico, que se deu em escala mais larga na Idade Antiga, Idade Média e Idade Moderna quando ainda não existia uma Biblioteconomia efetivamente especializada. Porém, crê-se que o ideário técnico-normativo (o técnico como processo de aplicação e o normativo como princípio ou regra que rege a aplicação) da Biblioteconomia predomina no período contemporâneo, e que a perspectiva de organizar e tratar a informação não é mais vista somente como elemento artístico ou estético, mas, principalmente, como elemento para acesso, recuperação e uso da informação.

Esse ideário técnico-normativo instiga a construção de relações físicas (sistemas de informação e recuperação da informação com o usuário) cognitivas (construção de conhecimento pelo usuário a partir da interação com as representações e os serviços da biblioteca) e sociais (relação humana mais ampla entre o usuário, a biblioteca e o bibliotecário como fundamento para uma construção coletiva da informação) no seio da Biblioteconomia

Enfim, observa-se que há um conjunto de estudos e práticas que auxiliaram na construção de uma tecnicidade, normatividade e cientificidade da Biblioteconomia.

\section{Estudos em organização e tratamento da informação: o embrião técnico-normativo da Biblioteconomia}

Acredita-se que pensar a Biblioteconomia como uma disciplina profissional a partir de uma perspectiva que envolve os construtos acadêmicos e a prática da profissão demanda uma compreensão sobre sua funcionalidade no seio do tratamento e organização da informação. É muito comum, aliás, reconhecer, na Biblioteconomia, a importância dos estudos sobre organização e tratamento da informação como um dos pilares de sua existência e consolidação no campo das práticas técnicas, normativas e profissionais.

Essa reflexão leva a uma contextualização histórica, principalmente quando a Biblioteconomia se estabelece como escola nas grandes universidades dos Estados Unidos e da Europa em fins do século XIX, primando por estudos de organização, representação e tratamento da informação, principalmente a partir das concepções técnicas e normativas da classificação, catalogação e indexação, além dos estudos sobre linguagens documentárias e elaboração de bibliografias (esta última já ocorria desde a ldade Antiga e de forma mais enfática desde os séculos XVI e XVII), e, mais recentemente (a partir da segunda metade do século XX), de recuperação da informação.

Nos Estados Unidos, em particular no século XIX, houve uma efervescência no que tange ao desenvolvimento de estudos para organização e tratamento de materiais bibliográficos, visando à recuperação da informação, especialmente em periódicos e, por conseguinte, à ampliação do processo de comunicação científica.

Ortega (2004, p.12) afirma que "A Biblioteconomia nos Estados Unidos, no final do século XIX, foi marcada por sua sedimentação e por inovações técnicas e tecnológicas". Destacam-se dois grandes momentos que valorizam o desenvolvimento dos estudos sobre organização e tratamento da informação nos Estados Unidos: por um lado, os estudos sobre representação, que compreende, em especial, a classificação, a indexação e a catalogação, e, por outro lado, o desenvolvimento da Escola de Biblioteconomia de Chicago, a partir da década de 1920, que valorizava os estudos sobre recuperação da informação (Shera, 1957).

Com relação ao primeiro momento, Smiraglia (2002, p.330) destaca que "No século dezenove, Panizzi (1841), Cutter (1876) e Dewey (1876) desenvolveram muitas ferramentas pragmáticas (isto é, catálogos e classificações), explicando como eles interpretavam os princípios nos quais suas ferramentas eram construídas".

Especificando cada contribuição envidada pelos estudiosos, Anthony Panizzi publicou as Regras para a Compilação de um Catálogo, iniciando o acesso ao assunto de uma obra por meio de um vocabulário controlado (Olson, 2002).

De acordo com Mey (1995), Charles Ami Cutter, bibliotecário norte-americano, em 1876, publicou suas Regras para um Catálogo Dicionário: como era de fácil entendimento, incluía a catalogação de assuntos.

Já Dewey pode ser considerado um dos grandes expoentes da classificação bibliográfica, com a elaboração da Classificação Decimal de Dewey (CDD), em 1876 (a 
primeira edição foi anônima), que pode ser considerada a mais utilizada nas bibliotecas de todo o mundo até os dias atuais, promoveu uma nova dimensão acerca de uma proposta de classificação, especialmente pela sua dimensão decimal. Olson (2002) afirma que a CDD é utilizada em aproximadamente 135 países, além de traduzida em aproximadamente 30 idiomas.

Já no que se refere ao segundo aspecto, a Escola de Biblioteconomia de Chicago promove um largo passo para se pensar procedimentos técnicos (processos que envolvem a organização e recuperação de informação) e normativos (princípios para composição epistemológica da Biblioteconomia). Shera (1957) afirma que um dos grandes princípios normativos e teóricos que norteiam a Biblioteconomia e a própria Ciência da Informação é a recuperação da informação.

A partir disso, a organização e o tratamento da informação respondem como elementos cruciais da Biblioteconomia, compreendendo, a partir da organização, os procedimentos para representação da informação que visam à recuperação da informação e ao tratamento da informação que envolve a descrição de todos os documentos.

Em suma, a organização e o tratamento da informação envolvem processos de representação e descrição de documentos, tais como as práticas de catalogação, classificação, indexação, linguagens documentárias, entre outras que correspondem a fundamentos normativos que norteiam a Biblioteconomia.

\section{Estudos funcionalistas de bibliotecas e bibliotecários: processos de consolidação técnico-normativa da Biblioteconomia}

Os estudos das funções sociais da biblioteca e do bibliotecário tornaram-se muito comuns no início do século XX, especialmente a partir da Escola de Biblioteconomia de Chicago. Como destaque dessa escola, é possível conceber dois nomes: Pierce Butler e Jesse Shera. De antemão, é preciso estabelecer que teorias funcionalistas inspiraram essa escola.

É preciso observar que as teorias funcionalistas se estabeleceram fortemente no âmbito dos estudos sobre cultura e natureza humana e foram se consolidando em outras áreas do conhecimento, como a Filosofia, Sociolo- gia, Antropologia, Linguística, Direito, Biblioteconomia etc.

O funcionalismo foi se desenvolvendo desde o século XVIII, apresentando como expoentes Durkheim, Herbert Spencer e René Worms - chamados de pré-funcionalistas -, a partir de concepções funcionais sistêmicas. No entanto, é no início do século XX que o funcionalismo se estabelece como teoria social, principalmente no seio da Antropologia, com Bronisllaw, Malinowski e Radcliffe-Brow.

Malinowski é o primeiro a teorizar sobre o funcionalismo quando concebe o significado de função diretamente ligado à satisfação de uma necessidade. Conforme Malinowski (1977, p.155) "A função significa sempre a satisfação de uma necessidade, desde a simples ação de comer até a execução sacramental, em que o fato de receber a comunhão se inscreve em todo um sistema de crenças, determinadas pela necessidade cultural [...]".

Retomando o pensamento dos estudiosos da Escola de Biblioteconomia de Chicago, observa-se que, no contexto relativo a Butler, é necessário trazer à baila sua obra "Introduction to Library Science", publicada em 1933 e onde discute a bibliografia, contemplando sua relevância desde que haja clareza sobre suas finalidades. Butler (1971) afirma ainda que seria preciso deslocar a função social das bibliotecas e dos bibliotecários dos processos para as funções.

No que concerne a Shera (1970), seu discurso está eminentemente voltado para a função da informação na sociedade. Para tanto, o estudioso comenta que houve o desenvolvimento de estudos diversos para entender a função e a importância das bibliotecas e de seus serviços (e também de arquivos, museus, centros de documentação e cultura etc.) para a sociedade.

Percebe-se, a partir dos estudos da Escola de Biblioteconomia de Chicago, que há uma percepção técnica e normativa para a área de Biblioteconomia tanto no contexto acadêmico quanto na prática profissional do bibliotecário. É preciso salientar que houve críticas a essa escola, pois, embora deliberasse estudos sobre administração de bibliotecas, serviços de informação e suas concepções funcionais, não sustentava uma efetiva abordagem científica. 
A percepção técnica ocorre em virtude de que as pesquisas buscavam mapear centros de informação e suas funções, visando constituir sua importância dentro do contexto social. Para tanto, seria necessário apresentar produtos e serviços, a fim de resolver problemas específicos das bibliotecas e outros centros de informação. Esse discurso está relacionado à pesquisa técnica conceituada porBunge (1980).

A percepção normativa ocorre em virtude de que, a partir das funções das bibliotecas, seria preciso estabelecer princípios que regessem sua atuação, desde seus processos de organização, representação e tratamento da informação, passando pelos processos de disseminação, acesso e uso da informação pelo usuário. Isso significa dizer que é fundamental compreender a função e a importância dos documentos (acervo), assim como dos recursos de informação (equipamentos tecnológicos e de infraestrutura, por exemplo) que, conforme Wilson (1989), envolvem elementos produzidos interna e externamente relacionados à gestão da informação, recorrendo sempre que preciso às tecnologias da informação) e serviços de informação, visando a desenvolver procedimentos para uma efetiva recuperação pelos usuários.

\section{Estudos centrados nos usuários: construção de uma percepção normativa e científico-cognitiva da Biblioteconomia}

A origem dos estudos de usuários remonta a uma proposta inicialmente normativa, uma vez que estimulavam a elaboração de princípios que pudessem reger o uso dos serviços de uma biblioteca, bem como as características de um determinado grupo de usuários para identificar o que utilizam para seu cotidiano. Segundo Wilson-Davis (1977), as pesquisas sobre estudos de usuários podem ser de dois tipos: a) Estudos centrados na biblioteca: a investigação de como as bibliotecas e os centros de informação são utilizados, e b) Estudos centrados no usuário: como um grupo particular de usuários obtém a informação necessária para conduzir seu trabalho.

Ressalta-se que os estudos de usuários começam a se desenvolver em meados da década de 1940, tendo sua primeira grande institucionalização, em 1948, na Conferência da Royal Society, onde foram apresentados diversos estudos sobre as necessidades dos usuários.
Destaca-se ainda a Conferência Internacional de Informação Científica em Washington, em 1958, com a apresentação de vários trabalhos sobre estudo de usuários (Figueiredo, 1994).

Dessa maneira, pode-se afirmar que os estudos de usuários seguem de forma mais clara a percepção de uma trajetória técnica, normativa e científica da Biblioteconomia. Antes de justificar os motivos pelos quais os estudos de usuários se inserem nesses três vieses, é pertinente indicar que sua aplicação apresenta três princípios e processos (normas e técnicas) gerais, conforme revela Cunha (1982):

a) Técnicas para análise documentária:

- Análise de conteúdo: serve para responder a questões do tipo: Quem diz alguma coisa, para quem, como, por que e com que perspectiva e/ou limitação?;

- Análise de citações: serve para identificar citações, autores e títulos mais utilizados em uma biblioteca;

- Documentos de biblioteca: utilizam-se para análise de materiais mais utilizados: fichas de empréstimo, pedidos de bibliografia, registro de perguntas feitas à seção de referência, formulários de empréstimo entre bibliotecas (e de comutação bibliográfica) etc.

- Diários: consiste no registro, pelos usuários, da quantidade e tipo de canais de informação utilizados num determinado período.

b) Técnicas para observação:

- Observação participante não sistemática: também chamada de observação participante não estruturada ou não controlada, é aquela em que um participante vai captando os acontecimentos, fazendo o papel de um repórter, sem, entretanto, participar ou influir no fluxo dos acontecimentos;

- Observação participante: o observador conta com recursos de controle, podendo promover estruturação ao processo de observação.

c) Técnicas para perguntas: são as técnicas mais utilizadas e constam de:

- Questionário: é a técnica mais utilizada;

- Entrevista: é a segunda técnica mais utilizada;

- Técnica de Delfos: é uma técnica para a previsão do futuro, sendo utilizada pela primeira vez em 1966, por OlafHelmer. 
Ainda podem ser destacadas mais duas técnicas para perguntas, mas que não são comumente utilizadas no Brasil:

- Técnica do Incidente Crítico: envolve a descrição de comportamentos que se configuram na identificação de atos relevantes, visando a conceber conteúdo sobre o objetivo do ato e suas consequências e efeitos (Flanagan, 1973).

- (Delphi) Grupos Focais: é uma técnica de pesquisa qualitativa composta por pequenos grupos de pessoas que se reúnem para discutir um tópico específico. A interação do grupo, além de técnicas como entrevistas, é um dado da pesquisa a ser considerado e não simplesmente o processo de pergunta e resposta. O propósito do grupo focal é gerar ideias, opiniões, atitudes e perspectivas (Carlini-Cotrim, 1996).

A partir da exposição das técnicas e das normas para estudos de usuários, pode-se afirmar o caráter técnico-normativo da Biblioteconomia porque insere princípios e processos técnicos, documentais, estatísticos e metodológicos para compreender questões inerentes ao uso de documentos, avaliação de serviços, avaliação de acervo, planejamento de serviços, comportamento de usuários e necessidades de informação.

Percebe-se que essa trajetória normativa é enfaticamente constituída entre 1948 até o final da década de 1970, quando se consolidam os estudos quantitativos de usuários que buscam responder a algumas perguntas, dentre as quais se enfatiza: a) quem usa os serviços da biblioteca?; b) quanto eles usam os serviços da biblioteca? e c) utilização de dados demográficos (sexo, idade, raça, estado civil, educação).

Entende-se ainda que os estudos de usuários são uma das principais estruturas para consolidação de uma percepção científico-cognitiva da Biblioteconomia: científica porque pensa o usuário como instrumento ontológico e dinâmico que utiliza serviços de informação das bibliotecas a fim de se apropriar de um sentido de informação e, por conseguinte, suprir suas necessidades; cognitiva porque, a partir dessa apropriação de informação, é possível que o usuário construa conhecimento de forma mais efetiva e sólida.

Essa configuração científico-cognitiva pode ser refletida nos estudos qualitativos de usuários que, de acordo com Ingwersen (1992), tem como principal marco a Conferência de Copenhaguen, ocorrida em 1977. Esses estudos buscam compreender basicamente: a) a adaptação dos serviços da biblioteca à necessidade do usuário; b) por quais motivos os clientes usam seus serviços; c) os benefícios oferecidos; d) como pode ser feito aperfeiçoamento da apresentação dos seus serviços; e e) as características da organização em que o bibliotecário trabalha.

Nos estudos qualitativos de usuários, há uma diversidade de propostas, tais como: modelo de informação com valor agregado de Taylor (1982) que prima pela facilidade de uso (formatação, ordenação e acessibilidade física) e qualidade (precisão, alcance, atualidade e eficácia); Sense Making de Dervin, que, conforme Ferreira (1997), ocupa-se da necessidade de fazer sentido sobre determinadas ações e práticas da vida; Kuhlthau (1999), que estabelece um modelo construtivista para observação do processo da busca da informação, que prevêas seguintes etapas: início, seleção, exploração e formulação; e os estudos de usabilidade que são desenvolvidos para sistemas de informação automatizados, visando a observar como os usuários agem e interagem de forma mental e física com o produto.

Todavia, é fundamental reconhecer que esses estudos não seguem uma escala linear e/ou evolutiva: eles coexistem e se complementam para compreender de forma mais ampla a realidade dos usuários e suas construções cognitivas.

\section{Da relação entre Biblioteconomia e Ciência da Informação: construtos institucionais para uma percepção técnica, normativa e científica}

É relevante afirmar que a base da construção técnica, normativa e científica da Biblioteconomia, especialmente a partir da década de 1960, deve-se ao estabelecimento institucional da relação com a Ciência da Informação.

Observa-se que não somente a Ciência da Informação como campo do conhecimento contribuiu para o desenvolvimento da Biblioteconomia como disciplina profissional, como a Biblioteconomia contribuiu para um construto epistemológico da Ciência da Informação, principalmente a partir dos estudos sobre organização e 
tratamento da informação, além da recuperação da informação. Ao falar sobre a relevância da Biblioteconomia para auxiliar a construção da Ciência da Informação, Foskett (1980) menciona uma velha arte da Biblioteconomia, que promoveu subsídios para o advento da Ciência da Informação. Exemplo maior disso é a contribuição de Ranganathan para os estudos de recuperação da informação na Ciência da Informação, principalmente através da criação do Classification Research Group (Grupo de Classificação e Recuperação), na Inglaterra (Foskett, 1973).

Em outras palavras, a relação entre Biblioteconomia e Ciência da Informação ocorre em uma perspectiva de reciprocidade, que pode ser ratificada em Le Coadic (2004, p.2), quando declara que"A Ciência da Informação nasceu da Biblioteconomia, tomando, assim, como objeto de estudo a informação fornecida pelas bibliotecas. A Ciência da Informação construiu-se e se fundamentou atualmente sobre essa base informacional". Isso significa dizer que a Biblioteconomia, principalmente a partir de estudos nos Estados Unidos da vertente tecnicista, serviu de base para o advento da Ciência da Informação ao mesmo tempo em que o desenvolvimento científico e tecnológico da Ciência da Informação contribuiu para os construtos acadêmico-profissionais de Biblioteconomia.

É necessário realçar que a Documentação de Otlet e La Fontaine na Europa também foi fundamental para apoiar o desenvolvimento científico e tecnológico da Ciência da Informação, mesmo diante da "Antipatia política" que a escola norte-americana apresentava com a Documentação na Europa e vice-versa. Targino (1995, p.12) afirma que a"Ciência da Informação emergiu como decorrência do processo de evolução da Biblioteconomia e Documentação, e configura-se, portanto, como o conjunto de conhecimentos relativos à origem, à coleta, à organização, ao armazenamento, à recuperação [...]".

Pode-se pensar também que essa relação, por um lado, promoveu maior densidade teórico-epistemológica à Biblioteconomia, mas, por outro lado, promoveu uma ampla especialização ao pensamento da área com um conjunto de percepções que ora se estabelecem isoladamente, ora de forma relacional. De outra forma, essa relação promoveu um fortalecimento institucional recíproco a Biblioteconomia e a Ciência da Informação, de sorte que houve um processo de departamentalização nas universidades, precipuamente no Brasil.

Nehmy et al. (1996, p.23) revelam sobre a departamentalização que:

As Ciências Sociais tiveram uma experiência de institucionalização através de uma crescente especialização de suas disciplinas - a Sociologia, a Economia, a Ciência Política e a Antropologia - formando assim comunidades específicas de pesquisadores. A Ciência da Informação segue o caminho inverso, constituindo-se como especialidade acadêmica a partir da formação pós-graduada de profissionais de variadas origens. Se a departamentalização das Ciências Sociais se dá por especialização, favorecendo a não existência de consenso entre seus praticantes, vamos dizer assim, maduros, na Ciência da Informação esta ausência já está colocada pelos iniciantes dessa disciplina que chegam ao campo já socializados como profissionais de outras áreas de atuação.

É possível afirmar que a citação de Nehmy et al. (1996) focaliza o nicho teórico de uma área de acordo com sua generalidade ou especificidade. É comum, por exemplo, cursos de graduação em Ciências Sociais que englobam Ciência Política, Sociologia e Antropologia, com a pós-graduação com especialidade em um dos três campos. Essa especialidade na pós-graduação, em sua maioria, é constituída por profissionais dessas três disciplinas que já vêm com uma visão relativamente acurada dos pressupostos pregados pela área.

A Ciência da Informação já segue o caminho disciplinar inverso, uma vez que pode ser pensada a partir da constituição de departamentos, faculdades, escolas ou institutos de Ciência da Informação em que estão inseridos comumente os cursos de Biblioteconomia em larga escala; Biblioteconomia/Arquivologia em escala razoável, mas em constante crescimento; Biblioteconomia/Arquivologia/Museologia em escala pequena.

Vale ressaltar que os cursos de Museologia, em muitos casos, não estão vinculados a departamentos de Ciência da Informação, como ocorre na Universidade Federal da Bahia (UFBA), Universidade Federal do Pará (UFPA), Universidade Federal de Pernambuco (UFPE), entre outras. Todavia, academias de Ciência da Informação, como a Escola de Ciência da Informação da Universidade Federal de Minas Gerais (UFMG) e a Faculdade de Ciência da 
Informação da Universidade de Brasília (UnB), contemplam os cursos de Museologia. Inclusive, essa realidade não é tão surpreendente em virtude de que a Coordenação de Aperfeiçoamento de Pessoal de Nível Superior (CAPES) não considera a Museologia como uma disciplina da Ciência da Informação (Coordenação de Aperfeiçoamento de Pessoal de Nível Superior, 2009).

Já na pós-graduação em Ciência da Informação, que é um campo geral e mais amplo do que o estabelecido disciplinarmente na graduação, ocorre uma evasão muito grande de profissionais graduados em áreas afins, como Computação, Administração, Ciência Contábeis etc., além dos graduados em Biblioteconomia e Arquivologia. Isso ocorre em virtude de que a finalidade da graduação é formar profissionais, enquanto a finalidade da pós-graduação é formar pesquisadores.

A elucidação para esse caso reside na finalidade científica. As Ciências Sociais que contemplam Ciência Política, Sociologia e Antropologia estão voltadas para o entendimento do mundo, pois se configura uma ciência clássica, eminentemente reflexiva. Já a Ciência da Informação, como ciência aplicada, tem a finalidade de resolver problemas de informação. Sua relação com a Biblioteconomia, Arquivologia e Museologia demanda um caráter disciplinar institucional voltado para um processo de aplicação profissional.

Desse modo, a partir dessa concepção institucional, entende-se que um dos principais contributos técnicos da Ciência da Informação para a Biblioteconomia está circunscrito no efetivo uso das tecnologias de informação e de comunicação, especialmente aplicadas aos estudos e práticas profissionais relativas aos sistemas de informação e recuperação da informação em bibliotecas e outros centros de informação e na própria Web.

Vale ressaltar que o advento da Ciência da Informação é fruto do desenvolvimento científico e tecnológico que a sociedade enfrentou, especialmente, a partir da II Guerra Mundial, visando a resolver os problemas referentes à explosão informacional (Wersig, 1993; Saracevic, 1996). É pertinente ressaltar a importância da Vannevar Bush como estudioso dos problemas da explosão informacional e das configurações tecnológicas, conquistando evidência no período da II Guerra Mundial. Carvalho Silva e Freire (2012, p.14) admitem que "Para a atuação da Ciência da Informação é de crucial relevância o uso das tecnologias de informação e comunicação, pois ele favorece amplamente o processo de organização, difusão, acesso e gerenciamento da informação, além de condicionar a Ciência da Informação a atuar a partir de qualquer suporte documental".

Esse desenvolvimento da Ciência da Informação no âmbito das tecnologias favoreceu de forma efetiva a inserção dos equipamentos tecnológicos na Biblioteconomia e no cotidiano da atividade profissional como a representação da informação (catalogação, classificação e indexação) a partir da inserção das redes colaborativas, bem como do atendimento ao usuário, que envolve o serviço de referência virtual e a ascensão do usuário remoto, promovendo maior dinamicidade e opção de estudo e aplicação profissional para a Biblioteconomia. 0 usuário remoto é representado por aqueles que podem ou não ter ligação com a instituição e que o contato com o centro de informação e com os bibliotecários se dá através de telefone, fax ou virtualmente (e-mail, reservas, consultas online etc.). Qualquer tipo de biblioteca - escolar, universitária, especializada, pública ou mesmo um museu e um arquivo -, pode oferecer serviços a usuários remotos (Garcez; Rados, 2002).

Já em termos normativos, as contribuições da Ciência da Informação estão mais definidas em suas relações disciplinares e temáticas e podem ser destacadas:

a) ATeoria Matemática da Comunicação de Shannon e Weaver (1949) que primam pela transmissão da mensagem a partir do seu caráter técnico (instrumentos físicos que dão suporte a informação como o papel), semântico (significado da mensagem atribuído pelo receptor) e pragmático (eficiência da mensagem) e;

b) Recuperação da informação, principalmente com a Lei de Mooers que se configura como princípio bastante voltado para aplicação em bibliotecas contemplando o uso da informação pelo usuário.

Esses princípios e regras de organização, uso e recuperação da informação promoveram subsídios mais sólidos para o desenvolvimento da parte mais técnica da Biblioteconomia (organização e tratamento da informação).

Assim, é inegável que o caráter técnico-normativo da Biblioteconomia e as influências da Ciência da Informação nesse sentido. Técnico porque insere estudos e 
práticas concernentes a tecnologia na Biblioteconomia. Normativo em virtude do estabelecimento de princípios, regras ou leis que governam os fluxos da Biblioteconomia, o que instiga um diálogo mais amplo com outras áreas consideradas mais densas cientificamente.

Inclusive, a discussão se insere em uma tessitura epistemológica na definição de problemas e objeto para uma solidificação científica. Goffman (1970) ao falar da interdisciplinaridade entre Ciência da Informação e Biblioteconomia pondera que o fato da Biblioteconomia ainda não ter definido seus problemas, demandam uma necessidade de recorrer à Ciência da Informação para obter a respeitabilidade acadêmica que lhes falta, principalmente porque uma disciplina não pode se legitimar se é restrita a uma instituição como a biblioteca.

Todavia, acredita-se que a Ciência da Informação promove subsídios para uma prática científica da Biblioteconomia, embora seja muito comum a negação de uma cientificidade da Biblioteconomia. Credita-se essa contribuição da Ciência da Informação o desiderato dos paradigmas, principalmente cognitivo e social ou sociocognitivo (Hjørland; Albrechtsen, 1995; Hjørland, 2003).

O paradigma cognitivo surge de vários estudiosos, tais como Brookes (1980) que se apropria dos três mundos de Popper (1973); Ingwersen (1992) observa de que forma os processos informativos transformam ou não o usuário, entendido em primeiro lugar como sujeito cognoscente; Belkin (1980) que estuda os estados anômalos do conhecimento. Essa teoria, segundo Capurro, (2003) parte da premissa de que a busca de informação tem sua origem na necessidade "need" que surge quando existe o mencionado estado cognitivo anômalo, no qual o conhecimento ao alcance do usuário, para resolver o problema, não é suficiente.

O paradigma social recebe influência de diversos filósofos: Wittgenstein, Heidegger e Foucault. Birger Hjørland desenvolveu, junto com Hanne Albrechtsen um paradigma social-epistemológico chamado análise de domínio "domain analysis" no qual o estudo de campos cognitivos está em relação direta com comunidades discursivas "discourse communities", ou seja, com distintos grupos sociais e de trabalho que constituem uma sociedade moderna. O paradigma social mostra que os campos cognitivos sensitivos, de recepção e de interpretação estão diretamente relacionados aos contatos com as comunidades e os grupos sociais que constituem a sociedade (Capurro, 2003).

Essa contribuição ocorre a partir do momento em que a percepção de paradigma sócio-cognitivo pode instigar a Biblioteconomia a pensar a construção social que permeia os serviços da biblioteca, as atividades gerenciais desenvolvidas pelos bibliotecários nas instituições, bem como as relações sociais entre usuários, bibliotecários, biblioteca e os processos de acesso, uso, apreensão e apropriação da informação como subsídios relevantes do paradigma sócio-cognitivo.

Pode ainda conceber a aplicação de teorias sociais como o construtivismo social como prega Cronin (2008) concebendo uma virada sociológica na Ciência da Informação que pode também ser aplicada ao contexto social da Biblioteconomia.

\section{Conclusão}

A Biblioteconomia pode ser compreendida como uma disciplina profissional em constante processo de aprimoramento técnico-normativo, pois sua história mostra sua construção e crescimento em termos de atividades organizacionais, de recursos e serviços de informação e do acesso e uso da informação, visando a satisfação das necessidades dos usuários.

Todo esse caminhar da Biblioteconomia deve valorizar o seu caráter técnico-normativo, pois, embora bastante desvalorizado no cotidiano da área, os estudos de organização e tratamento da informação buscaram desenvolver práticas para resolver problemas nas bibliotecas.

Ainda mais, a construção técnico-normativa da Biblioteconomia contribuiu, sobretudo, para o advento da Ciência da Informação favorecendo uma forte relação institucional entre ambas, seja no contexto acadêmico-científico, seja no contexto do cotidiano profissional da Biblioteconomia.

Desse modo, acredita-se que a Biblioteconomia, mesmo em sua postura técnico-normativa tem condições de produzir ciência a partir do momento em que busca resolver problemas gerais que norteiam a informação nas bibliotecas e seus elementos técnicos (processos) por meio de suas normas (princípios como leis bibliomé- 
tricas, representações como a catalogação, classificação, indexação, entre outras).

Por isso, acredita-se que a Biblioteconomia se configura essencialmente como uma técnica porque possui o caráter artístico da organização que compreende a representação e o tratamento da informação, assim como o caráter tecnológico do uso de computadores e sistemas de informação e recuperação da informação. Além disso, percebe-se que a Biblioteconomia também é essencialmente normativa, pois necessita fundamentalmente dos seus princípios para construir sua atuação acadêmico-profissional.

Porém, observa-se que a Biblioteconomia também possua o seu caráter científico, embora não seja originariamente uma ciência, mas é possível construir a prática científica a partir de seus fundamentos técnicos e normativos.

Da prática científica da Biblioteconomia verifica-se a importância da Ciência da Informação em oferecer métodos para resolução de problemas cruciais que po-

\section{Referências}

ASSOCIAÇÃO BRASILEIRA DE NORMAS TÉCNICAS. ABNT/CB 14: informação e documentação. São Paulo: ABNT, 2006.

BELKIN, N.J. Anomalous states of knowledge as basis for information retrieval. The Canadian Journal of Information Science, v.5, p.133-143, 1980.

BROOKES, B.C. The foundation of information science. Journal of Information Science, v.2, n.1, p.125-133, 1980.

BUNGE, M. Ciência e desenvolvimento. São Paulo: Edusp, 1980.

BUTLER, P. Introdução à ciência da biblioteconomia. Rio de Janeiro: Lidador, 1971.

CAPURRO, R. Epistemologia e ciência da informação. In: ENCONTRO NACIONAL DE PESQUISA EM CIÊNCIA DA INFORMAÇÃO, 5., 2003, Belo Horizonte. Anais... Belo Horizonte: UFMG, 2003. p.19.

CARLINI-COTRIM, B. Potencialidades da técnica qualitativa grupo focal em investigações sobre abuso de substâncias. Revista de Saúde Pública, v.30, n.3, p.285-293, 1996.

CARVALHO SILVA, J.L. Uma análise sobre a identidade da biblioteconomia: perspectivas históricas e objeto de estudo. Olinda: Edições Baluarte, 2010.

CARVALHO SILVA, J.L.; FREIRE, G.H.A. Um olhar sobre a origem da ciência da informação: indícios embrionários para sua caracterização identitária. Encontros Bibli, v.17, n.33, p.1-29, 2012. Disponível em: <http://www.periodicos.ufsc.br>. Acesso em: 11 maio 2012. dem variar desde um paradigma físico (envolve os processos de organização e recuperação da informação em diversos contextos físicos e tecnológicos em bibliotecas e espaços virtuais) passando por um paradigma cognitivo que busca pensar modelos (caráter normativo-científico de um espectro positivista) para desenvolver sistemas e representações considerando a realidade mental dos usuários e, finalmente, chegando ao paradigma social que insere uma reflexão densa sobre as práticas sociais e interacionistas que desenvolve as bibliotecas e os bibliotecários e os processos que permeiam as relações sociais entre bibliotecários e usuários.

Portanto, isso mostra que a Biblioteconomia tem uma tríade que se caracteriza no âmbito técnico-normativo-científico, sendo os primeiros procedimentos essenciais da área e o terceiro são procedimentos agregados em suas relações com a Ciência da Informação e outras áreas do conhecimento científico que pode ser, de forma particular, social (Sociologia, História, Educação, Administração etc.) ou tecnológico (Computação, Engenharia de Produção etc.).
COORDENAÇÃO DE APERFEIÇOAMENTO DE PESSOAL DE NÍVEL SUPERIOR. Tabela das áreas do conhecimento. Brasília: Capes, 2009. Disponível em: <http://www.capes.gov.br/ images/stories/download/avaliacao/TabelaAreas Conhecimento_0 42009.pdf>. Acesso em: 1 fev. 2011.

CRONIN, B. The sociological information science. Journal of Information Science, v.34, n.4, p.465-475, 2008.

CUNHA, M.B. Metodologias para estudo de usuários de informação científica e tecnológica. Revista de Biblioteconomia de Brasília, v.10, n.2, p.5-19, 1982.

CUTTER, C.A. Rules for a printed dictionary catalog. Washington: Government Printing Office, 1876.

DEWEY, M. A classification and subject index forcataloguing and arranging the books and pamphlets of a library. Amherst: Kingsport, 1876. Available from: <http://www.gutenberg. org/files/12513/12513-h/12513-h.htm>. Cited: 9 May 2012.

DIAS, E.W. Biblioteconomia e ciência da informação: natureza e relações. Perspectivas em Ciência da Informação, v.5, n.2, p.67-80, 2000.

ESPER, M.W. Normalização de habitação para locação social. In: SEMINÁRIO INTERNACIONAL DE LOCAÇÃO SOCIAL, 2008, Brasília. Anais... Brasília: Ministério das Cidades, 2008. p.1-41.

FERREIRA, A.B.H. Mini Aurélio: o dicionário da língua portuguesa. 8.ed. Curitiba: Positivo, 2010.

FERREIRA, S.M.S.P. Estudo de necessidade de informação: dos paradigmas tradicionais à abordagem sense-making. São 
Paulo, 1997. Disponível em: <www.eca.usp.br/nucleos/sense/ textos/>. Acesso em: 28 maio 2011.

FIGUEIREDO, N. Estudos de uso eusuários da informação. Brasília: Ibict, 1994.

FLANAGAN, J.C. A técnica dos incidentes críticos. Arquivos Brasileiros Psicologia Aplicada, v.21, n.5, p.99-141, 1973.

FOSKETT, A.C. A abordagem temática da informação. São Paulo: Polígono, 1973.

FOSKETT, D.J. Ciência da informação como disciplina emergente: implicações educacionais. In: HAGAR, E.G. (Org.). Ciência da informação ou informática? Rio de Janeiro: Calunga, 1980. p.52-69.

GARCEZ, E.M.S.; RADOS, G.J.V. Biblioteca híbrida: um novo enfoque no suporte à educação à distância. Ciência da Informação, v.31, n.2, p.44-51, 2002.

GOFFMAN, W. Information science: discipline or disappearence. Aslib Proceedings, v.22, n.12, p.589-596, 1970.

GOODE, W.J.; HATT, P.F. Alguns problemas na análise qualitativa e na análise do caso. In: GOODE, W.J.; HATT, P.F. Métodos em pesquisa social. 3.ed. São Paulo: Nacional, 1969. p.398-433.

HJØRLAND, B. Epistemology and the socio-cognitive perspective in information science. Journal of the American Society for Information Science and Technology, v.53, n.4, p.257-270, 2003.

HJØRLAND, B.; ALBRECHTSEN, H. Toward a new horizon in information science: domain-analysis. Journal of the American Society for Information Science and Technology, v.46, n.6, p.400-425, 1995.

HUSSERL, E. Lineamenti di ética formale: lezioni sull'etica e la teoria dei valori del 1914, a cura di Paola Basso e Paolo Spinicci. Firenze: Le Lettere, 2002.

INGWERSEN, P. Conceptions of information science. In: VAKKARI, P.: CRONIN, B. (Ed.). Conceptions of library and information science: historical, empirical and theoretical perspectives. Los Angeles: Taylor Graham, 1992. p.299-312.

KUHLTHAU, C. The role of experience in the information search process of an early career information worker: perceptions of uncertainty, complexity, construction, and sources. Journal of the American Society for Information Science, v.50, n.5, p.399-412, 1999.

LE COADIC, Y.F. A ciência da informação. Brasília: Briquet de Lemos, 2004.

MALINOWSKI, B. A teoria funcional. In: BIRNBAUM, P.C. Teoria sociológica. São Paulo: Hucitec, 1977. p.154-157.
MEY, E.S.A. Introdução à catalogação. Brasília: Briquet de Lemos, 1995.

NEHMY, R. et al. A ciência da informação como disciplina científica. Perspectivas em Ciência da Informação, v.1, n.1, p.9-25, 1996.

OLSON, H.A. The power to name: locating the limits of subject representation in libraries. Dordrecht: Kluwer Academic, 2002.

ORTEGA, C.D. Relações históricas entre biblioteconomia, documentação e ciência da informação. DataGramaZero: Revista de Ciência da Informação, v.5, n.5, 2004. Disponível em: $<w w w . d g z . o r g . b r>$.

PANIZZI, A. Rules for the compilation of the catalogue. In: PANIZZI, A. The catalogue of printed books in the British museum. London: British Museum, 1841. p.v-ix.

POPPER, K.R. Objective knowledge: an evolutionary approach. Oxford: Clarendon, 1973.

RANGANATHAN, S.R. The five laws of library science. Madras: Madras Library Association, 1931.

SARACEVIC, T. Ciência da informação: origem, evolução e relações. Perspectivas em Ciência da Informação, v.1, n.1, p.41-62, 1996.

SHANNON, C.E.; WEAVER, W. The mathematical theory of communication. Urbana: University of Illinois, 1949.

SHERA, J.H. Research and developments in documentation. Library Trends, v.6, n.2, p.187-206, 1957.

SHERA, J.H. Sociological foundations of librarianship. New York: Asia Publishing House, 1970.

SMIRAGLIA, R.P. The progress of theory in knowledge organization. Library Trends, v.50, n.3, p.330-349, 2002.

TARGINO, M.G. A interdisciplinaridade da ciência da informação como área de pesquisa. Informação \& Sociedade, v.5, n.1, 1995. Disponível em: <http://www.informacaoesociedade. ufpb.br>. Acesso em: 15 jul. 2010.

TAYLOR, R.S. Value-added processes in the information life cycle. Journal of the American Society of Information Science, v.33, n.5, p.341-346, 1982.

WERSIG, G. Information science: the study of postmodern knowledge usage. Information Processing \& Management, v.29, n.2, p.229-239, 1993.

WILSON, T.D. Towards an information management curriculum. Journal of Information Science, v.15, n.4/5, p.203-209, 1989.

WILSON-DAVIS, K. The centre for research on users studies: aims and functions. Asilib Proceedings, v.29, n.2, p.65-69, 1977. 
